\title{
Nuclear Fuel Cycle and Supply Chain (NFCSC) Technical Monthly February FY-20
}

The INL is a U.S. Department of Energy National Laboratory operated by Battelle Energy Alliance 


\section{DISCLAIMER}

This information was prepared as an account of work sponsored by an agency of the U.S. Government. Neither the U.S. Government nor any agency thereof, nor any of their employees, makes any warranty, expressed or implied, or assumes any legal liability or responsibility for the accuracy, completeness, or usefulness, of any information, apparatus, product, or process disclosed, or represents that its use would not infringe privately owned rights. References herein to any specific commercial product, process, or service by trade name, trademark, manufacturer, or otherwise, does not necessarily constitute or imply its endorsement, recommendation, or favoring by the U.S. Government or any agency thereof. The views and opinions of authors expressed herein do not necessarily state or reflect those of the U.S. Government or any agency thereof. 


\section{Nuclear Fuel Cycle and Supply Chain (NFCSC) Technical Monthly February FY-20}

Idaho National Laboratory Idaho Falls, Idaho 83415

http://www.inl.gov

Prepared for the

U.S. Department of Energy

Office of Nuclear Energy

Under DOE Idaho Operations Office

Contract DE-AC07-05ID14517 



\section{CONTENTS}



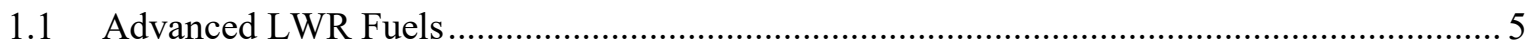



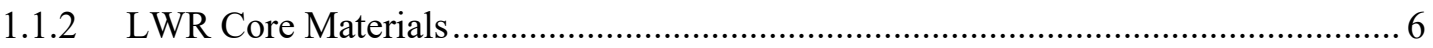

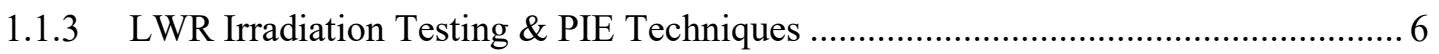

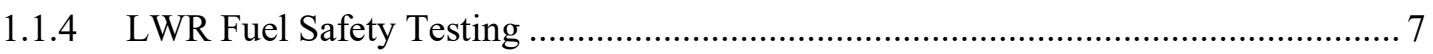



1.2.1 AR Irradiation Testing \& PIE Techniques ............................................................. 8

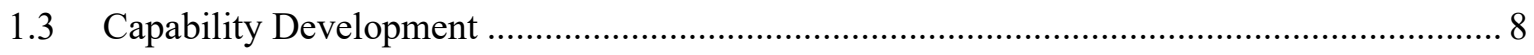

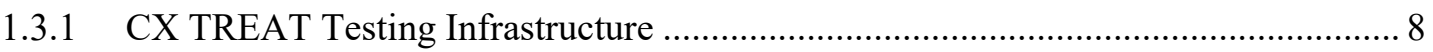

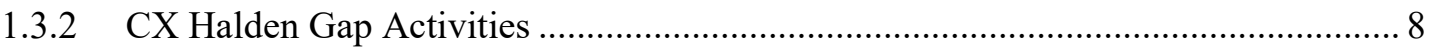

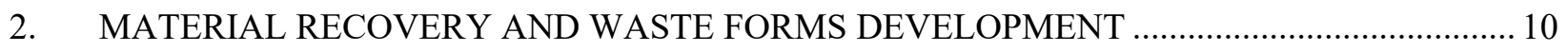

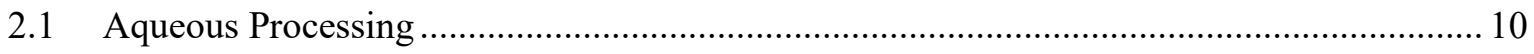

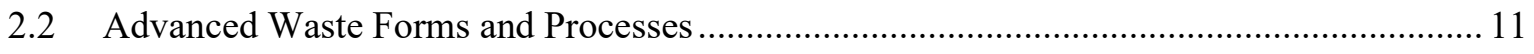

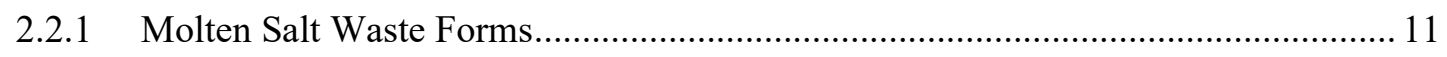

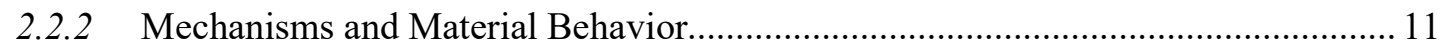

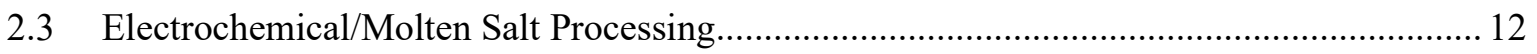



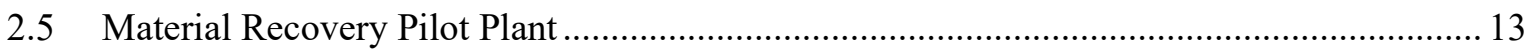

2.6 Polishing and Solidification (Extraction, Conversion, Downblending)............................... 13

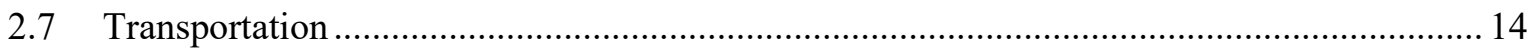

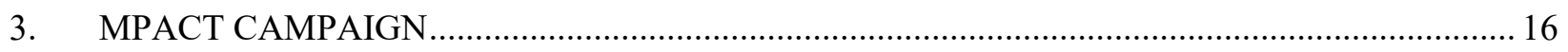

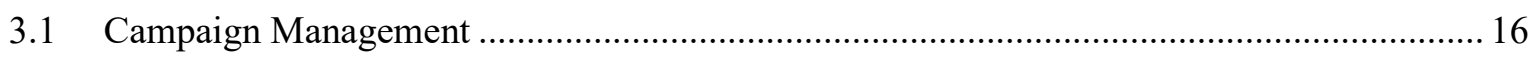

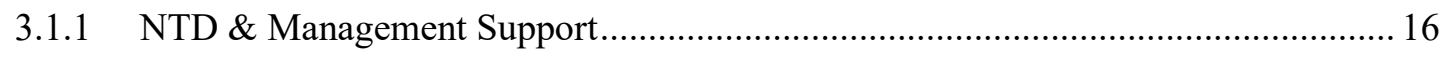

3.2 MRWFD/Advanced Nuclear Safeguards and Security Research ....................................... 16

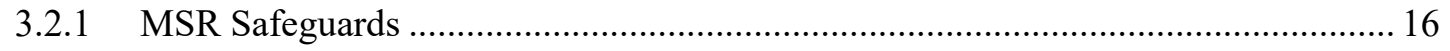

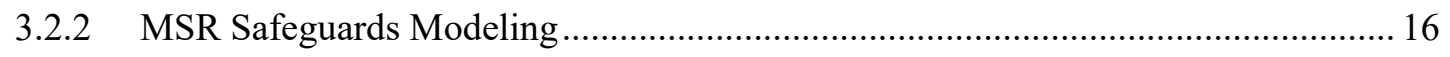



3.3 Safeguards and Security Supporting Technologies - Echem.......................................... 16

3.3.1 Bubbler for Measuring Density and Depth of Molten Salt .................................... 16

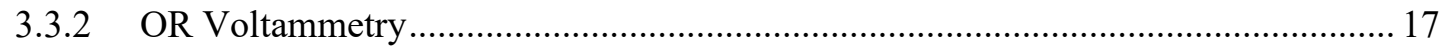

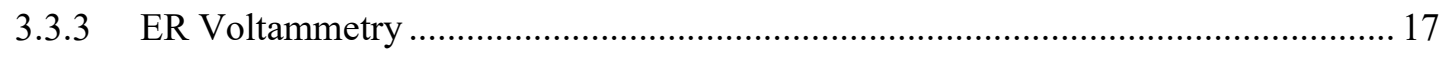

3.4 Safeguards and Security Milestone 2020 - Echem:......................................................... 17

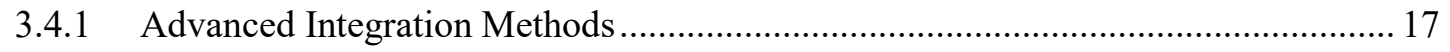

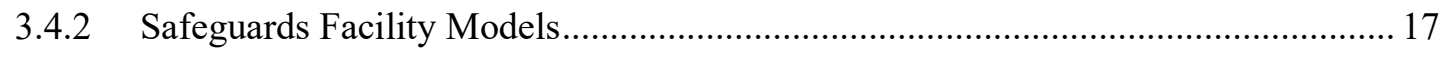

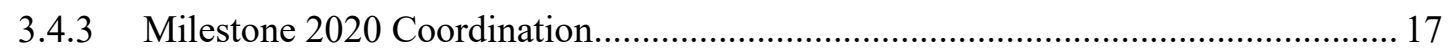




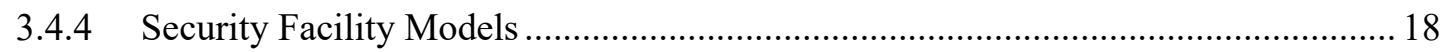

4. SYSTEMS ANALYSIS AND INTEGRATION (SA\&I) CAMPAIGN ...................................... 19

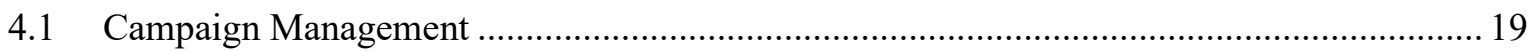

4.2 Nuclear Energy System Performance (NESP) ................................................................. 19

4.2.1 Technology Maturity \& Economic Performance Potential of Micro-reactors.......... 19

4.2.2 Impacts of Foreign Energy Transition Policies...................................................... 19

4.2.3 Factors Impacting Nuclear Energy Share ............................................................. 19

4.2.4 Re-use of Decommissioned Nuclear Assets ............................................................ 19

4.2.5 FCDP Development for Specific Advanced Reactors ............................................ 20

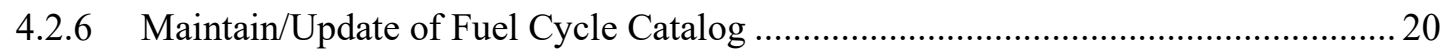

4.2.7 Transition Analysis Studies and Tools Development ............................................... 20

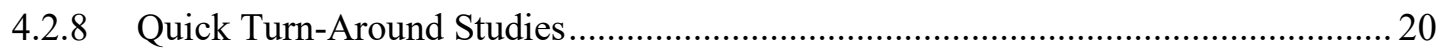

4.3 Economic And Market Analysis For Nuclear Energy Systems (EMANES) ........................ 20

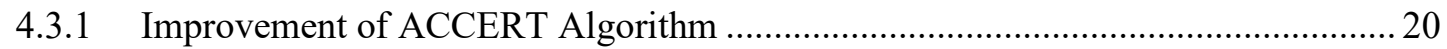

4.3.2 Daily Market Analysis of Load Following and Storage Impacts............................. 21

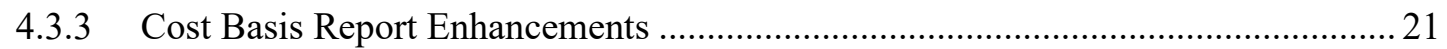

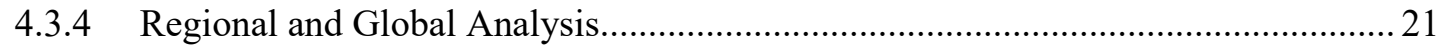

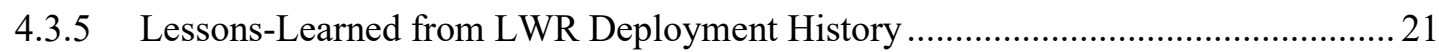



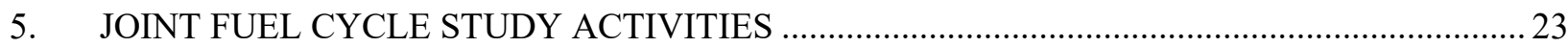

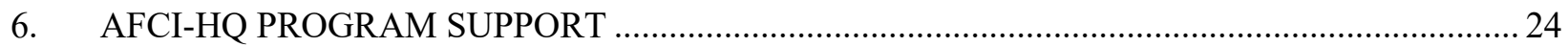

6.1 Innovations in Nuclear Technology R\&D Awards ............................................................... 25

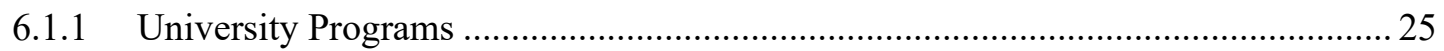

\section{FIGURES}

Figure 1. Ti-rich grain boundaries of the 4000 wpm Ti-doped $\mathrm{UO}_{2}$ samples. SEI SEM micrographs and the corresponding EDS elemental maps. ................................................. 6

Figure 2. ATF-2 rodlet in the carrier used to perform neutron radiography ............................................. 7

Figure 3. Overlay of ${ }^{1} \mathrm{H}$ NMR spectra of a mixture and isolated diastereomers....................................... 10

Figure 4. SEM photomicrographs of corroded surfaces of (a) and (b) DPF-280 and (c) and (d) DPF-336 after ASTM C1220 tests.

Figure 5. SEM photomicrographs of secondary phases formed when Stage 3 was triggered in tests with (a) DWPF batch glass, (b) DWPF HM glass, (c) and (d) DWPF blend glass. 


\section{Nuclear Fuel Cycle and Supply Chain (NFCSC) Technical Monthly February FY-20}

\section{ADVANCED FUELS CAMPAIGN}

\subsection{Advanced LWR Fuels}

\subsubsection{LWR Fuels}

[INL] For the upgraded hydrogen system in EFF, all materials from Thermal Technologies have been received. Work planning packages have been developed and crafts are being scheduled to upgrade the building detection system and install the upgraded hydrogen system. (M. Cole)

[LANL] An invited talk and poster were presented at the TMS 2020 conference by Dr. David Frazer and Dr. Tashiema Ulrich, respectively. The invited talk focused on nanomechanical testing methods at elevated temperatures on nanoscale cantilevers and at specific microstructural locations on nuclear fuels (e.g. $\mathrm{UO}_{2}, \mathrm{UN}$, and $\mathrm{U} 3 \mathrm{Si} 2$ ) on fresh fuel samples. This work highlights methods to collect quality data at lower length scales. The invited poster presented work on the modeling of the U-Si phase diagram, which improved upon the understanding of homogeneity ranges for U3Si2 and the USi2-x phase field as well as high temperature crystallographic studies to confirm computational efforts in NEAMS on the defect structures in these crystal systems. Both of these presentations highlight the impact and relevancy of work conducted within the Advanced Fuels Campaign to accelerate understanding of nuclear fuels for modern day reactors. (D. Frazer, T. Ulrich, J. White)

[LANL] High-density $\mathrm{UO}_{2}$ pellets (93\% TD) were obtained within a few minutes using a modified flash sintering (FS) method. FS is a sintering technique were electric field and current are applied to a ceramic compact to densify it. Traditionally, a DC electric field is applied. Previously, $91 \% \mathrm{TD} \mathrm{UO}_{2}$ pellets were obtained using traditional FS, however, the pellets were severely cracked due to high thermal stresses. Using modified FS, where an AC field is applied and the electric current flowing through the pellet is increased linearly with time, the sintering rate and thermal stresses were controlled, thus, eliminating cracking and obtaining high density pellets. Additionally, the AC electric field can eliminate the intrinsic $\mathrm{O} / \mathrm{M}$ gradient that a DC field would form, leading to differential sintering. Further characterization of the flash-sintered samples is planned, and the validated FS conditions will be applied as a starting point for FS studies on high density fuels. (R. Ingraci Neto, E. Kardoulaki)

[ORNL] A few $\geq 2000$ wppm Ti-doped $\mathrm{UO}_{2}$ samples sintered at $1400^{\circ} \mathrm{C}$ for $2 \mathrm{~h}$ and $1700^{\circ} \mathrm{C}$ for $10 \mathrm{~h}$ holding times produced better microstructures with considerably lower porosity and slightly higher densities (96-97\% TD) compared to the samples fabricated using longer holding times at $1350^{\circ} \mathrm{C}$ and $1700^{\circ} \mathrm{C}$. The level of Ti-rich phase precipitation also showed to be low in these samples (see Figure 1 below). However, the average grain sizes of these samples were $\sim 50 \mu \mathrm{m}$, which is lower than that of the samples $(60-75 \mu \mathrm{m})$ sintered for longer holding times. An undoped $\mathrm{UO}_{2}$ sample and few Ti-doped $\mathrm{UO}_{2}$ samples containing 1000, 2000, and $4000 \mathrm{wppm}$ Ti concentrations were prepared to determine their thermal diffusivity, followed by thermal conductivity, using laser flash analysis (LFA). (A. Nelson) 


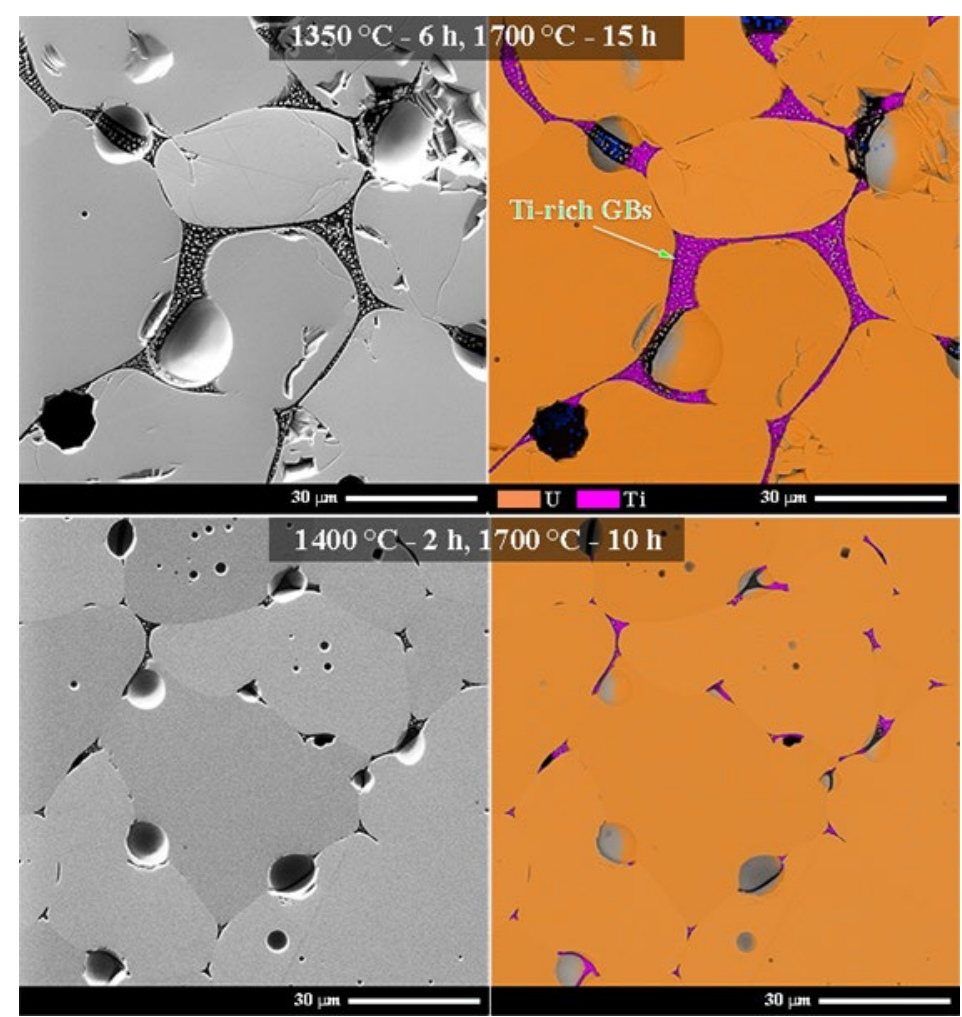

Figure 1. Ti-rich grain boundaries of the $4000 \mathrm{wpm}$ Ti-doped $\mathrm{UO}_{2}$ samples. SEI SEM micrographs and the corresponding EDS elemental maps.

\subsubsection{LWR Core Materials}

[LANL] Milestones were adjusted to fit reduced budget. Samples of irradiated FeCrAl specimens have been mounted and polished to prepare for microstructural analysis. A presentation was given by Ben Eftink at TMS 2020 in San Diego, California, titled, "Multiple Scale Mechanical Testing of Neutron Irradiated FeCrAl Alloys.” (B. Eftink)

\subsubsection{LWR Irradiation Testing \& PIE Techniques}

[INL] During the month of February, the Advanced Test Reactor was in Cycle 167A outage. ATF-2 remained at 244 effective full power days and ATF-2B1 (new configuration with general electric boiling water reactor type pins in Tiers 3 and 4) remained at 60 effective fuel power days of irradiation. Three 12in.-long pressurized water reactor type fuel pins with coated O-Zirlo cladding and $\mathrm{UO}_{2}$ fuel were fabricated for Westinghouse and installed in a newly fabricated ATF-2B holder to complete Milestone M2FT-20IN020203011, "New ATF-2 Tier 5/6 ready for new Westinghouse rodlets and ATR insertion," (due Feb. 29, 2020) on Feb. 27, 2020. (G. Hoggard)

[INL] The program has determined that all remaining original ATF-1 series capsules will not go back into the ATR for further irradiation, therefore all planned work for the 168A-1 and 168B-1 cycles has been cancelled. These capsules are currently stored in the ATR canal and will be shipped to HFEF in May. Design and analysis efforts to support new ATF-1 scope for Framatome are on track. Fuel rodlets are expected to ship to INL from Framatome-Richland in April. The ATF-CC (cladding creep) experiment has also been cancelled due to budget changes. (C. Murdock) 
[INL] Fixtures to perform PIE on ATF-2 rodlets have completed in-cell qualification. Test-fitting of a dummy ATF-2 rodlet in the carrier used to perform neutron radiography is shown in Figure 2, below. (F. Cappia)



Figure 2. ATF-2 rodlet in the carrier used to perform neutron radiography.

\subsubsection{LWR Fuel Safety Testing}

\subsubsection{LWR Modeling \& Analysis}

[ORNL] A journal article titled, "Impact of Control Blade Insertion on the Deformation Behavior of SiCSiC Channel Boxes in BWRs," submitted to Nuclear Engineering and Design, received favorable review comments with minor revisions suggested. The article is under revision and is expected to be published in the near future. This article presents the recent work focused on the impact of control blade position on the deformation and stress development in a SiC-SiC channel box in a BWR environment. (B. Wirth)

[ORNL] A study focused on the thermo-mechanical analysis of SiC-SiC cladding with SiC and Zircaloy spacer grids is under progress. The work objective is to understand the effect of mechanical constraints imposed by spacer grids on the deformation and stress development in the $\mathrm{SiC}-\mathrm{SiC}$ cladding under the conditions of circumferentially non-uniform power generation. The recent work includes mesh sensitivity studies and detailed analysis of the role of thermal and swelling strains on the deformation behavior and stress development in the cladding. (B. Wirth) 


\subsection{Advanced Reactor Fuels}

\subsubsection{AR Irradiation Testing \& PIE Techniques}

[INL] FAST-1 experiment assembly is now started. Fuel development activities have concluded, and actual fuel fabrication is in progress. Final weld development activities are nearing completion. Final capsule component fabrication experienced delays and some minor scope growth. The remainder of OA capsule components are now forecast to finish in mid-March. Preparations for the 168A-1 cycle are making progress and are on track. Preparations for shipment of the IRT1 and 4C (C5) capsules are making progress for a shipment in early March. (C. Murdock)

\subsection{Capability Development}

\subsubsection{TREAT Testing Infrastructure}

[INL] The replacement control and data collection replacement computer has not yet been delivered. Data collected from a parallel PTR setup using a time domain technique is being analyzed to verify to the model and determine repeatability and accuracy. (R. Schley)

\subsubsection{Halden Gap Activities}

\subsubsection{TREAT}

[INL] Preparations for experiment rodlet assembly were performed, including finalizing and qualifying welding parameters for the rodlet utilizing the newly modified welding-under-pressure system, and cleaning up threads on the 3-D printed capsules. (L. Emerson)

[INL] The design and analysis work for creating a capsule that is compatible with the ATF-2 irradiated fuel rods is making great strides. The team has settled on a design that successfully achieves all of the functional and operational requirement objectives and is designed with hot cell manipulator handling in mind. The neutronics ECAR was drafted and thermal models have been developed. The team issued an experiment execution plan and has begun ordering long-lead items needed for the experiment assembly. (L. Emerson)

[INL] Work continued on the underwater evaluation of pyrometers at HTTL and at TREAT. INL Is working on new instruments to be placed into MIMIC-N for testing. (T. Pavey)

[INL] We have demonstrated the capability of axial tension specimen machining using an out-cell mill. Qualification of this process and fixture manufacturing has been initiated. The FOR document for the mechanical testing has been submitted for review. (M. Bybee)

[INL] Installation of the additional 96 channels for the Hodoscope has been stopped. All equipment has been packed for storage until funding is sufficient to install new equipment. The electro-mechanical equipment at TREAT has been moved to a new location. Metrology finished the report on Separate Effects Tests (SET) of fission flux wires. Metrology is working on finishing up the gamma-spec counting on the MARCH-SERTTA Gamma pin to get a valid Power Coupling Factor (ECF). (T. Pavey)

[INL] The security liners (contamination control) for handling the MARCH-based experiment vehicles inside the HFEF hot cell are being fabricated and are expected at the end of March. The design of the incell handling and lifting fixtures continues. Requirements for the instrumentation and control system for the MARCH-based vehicles, which supports device assembly and testing before experiments are delivered to TREAT for irradiation were established and design efforts have commenced to support 
building this system. Work continued with TREAT and HFEF personnel to qualify the 15-Cask. The table and pit liner for HFEF window 5D are ready for installation. (M. Bybee)

[INL] The negotiations with AMET have concluded and a contract for the final design and fabrication of an end-cap welding system will be awarded once funding has been approved. A design review of the welding under pressure system was also completed during this period. Design engineers are working to incorporate comments on this system at which point BEA will begin fabrication. Lastly, the functional and operational requirements document for an electrical feedthrough was completed and detailed design has now been initiated. (M. Cole)

[INL] The procurement package for the closure plate is complete and bids have been requested from multiple vendors. A specification has been prepared for the closure plate stand in preparation for placement of a contract with Framatome. Progress has been made on the in-pile tube and out-of-core equipment design. (T. Maddock)

For more information on Fuels contact Steven Hayes (208) 526-7255. 


\section{MATERIAL RECOVERY AND WASTE FORMS DEVELOPMENT}

\subsection{Aqueous Processing}

[INL] The abstract submitted to Atalante 2020 conference titled, "From $\mathrm{H}_{5}$ dtpa to $\mathrm{H}_{4} \mathrm{Octapa}$ : Aminopolycarboxylate Radiometal Chelators for Trivalent Actinide Coordination," has been selected for a keynote presentation in the technical session "Actinide and Fission Product Chemistry." (P. Zalupski)

[ONRL] A variety of conditions were tested to further increase the diastereomeric ratio of the desired $(R, S)$ mTDDGA product. Unfortunately, the use of strong nonnucleophilic bases resulted in significant formation of vinyl product through deprotonation of the methyl hydrogen in 2-bromo-propanamide, followed by the subsequent elimination of bromide. So far, 1.0 equivalent of $\mathrm{NaH}$ as a base leads to the highest reaction yields $(>90 \%)$ and acceptable $d r$ ratio (favoring formation of desired $(R, S)$-diastereomer). Table 1 summarizes all the conditions that have been tested so far. We have confirmed that both diastereomers can be easily separated and isolated from the reaction mixture (see Figure 3 ). We will initiate the scale-up to produce $1 \mathrm{~kg}$ of $(R, S)$-mTDDGA as

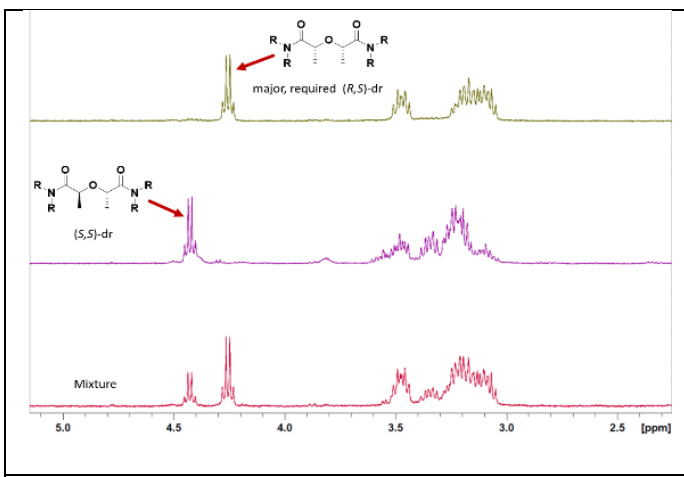

Figure 3. Overlay of ${ }^{1} \mathrm{H}$ NMR spectra of a mixture and isolated diastereomers. soon as the starting material, didecylamine, arrives. This chemical was ordered in October from AK Scientific, Inc. The manufacturer, in China, has the product ready to be shipped to US; however, since the shipments out of China are still heavily restricted, it is unclear when the product might arrive. We hope that this product will arrive soon to ensure completion of the milestone over the next two months. Overall, the new method is highly efficient.

Table 1. Optimization of the reaction conditions.

\begin{tabular}{|c|c|c|c|c|c|}
\hline \multirow[b]{2}{*}{ Base } & \multirow[b]{2}{*}{ Solvent } & \multirow[b]{2}{*}{ Temperature, C } & \multicolumn{2}{|c|}{ dr ratio } & \multirow[b]{2}{*}{ Elimination product } \\
\hline & & & $(\mathrm{R}, \mathrm{S})-\mathrm{dr}$ & $(5,5)-d r$ & \\
\hline $\mathrm{NaH}$ & THF & $>65$ & 1 & 0.55 & 0.04 \\
\hline $\mathrm{NaH}$ & THF & 50 & 1 & 0.55 & 0.05 \\
\hline NaHMDS & THF & 0 & 1 & 0.44 & 0.52 \\
\hline $\mathrm{NaHMDS}$ & THF & -20 & 1 & 0.48 & 0.55 \\
\hline $\mathrm{NaHMDS}$ & THF & 25 , then 0 & 1 & 0.48 & 0.52 \\
\hline KOtBu & THF & 50 & 1 & 0.46 & 0.71 \\
\hline KOtBu & DMF & 50 & 1 & 1 & 0.82 \\
\hline LDA & THF & -78 & - & - & - \\
\hline
\end{tabular}

The manufacturer indicates that 4-bromo-2,6-bis(bromomethyl)pyridine, the starting material for the synthesis of aqueous holdback agent, has been shipped (the product was ordered back in December). As soon as the starting material arrives, we will resume the synthesis of functionalized tris-pyridine product.

After a conversation with the collaborator at INL, the synthesis of known DOTA-base ligand was placed on hold. Alternative donating groups instead of picolinic acid have been proposed. We have tasked our computational scientist with confirming the ability of the new proposed ligands to bind An(III). The synthesis will resume as soon as we have an affirmative response. (S. Jansone-Popova) 


\subsection{Advanced Waste Forms and Processes}

\subsubsection{Molten Salt Waste Forms}

[ANL] Long-term tests initiated in FY-19 with two iron phosphate materials (DPF-280 and DPF-336) made with low and high salt waste loadings have been completed. Initial analyses of corroded surfaces show differences in the corrosion behaviors. Figures $4 \mathrm{a}$ and $4 \mathrm{~b}$ show high magnification SEM photomicrographs of DPF-280 made to represent low salt loadings. The material was essentially a homogeneous glass, but the reacted surface reveals an abundance of inclusion phases that were exposed as the glass dissolved. Figures $4 \mathrm{~b}$ and $4 \mathrm{c}$ show high magnification SEM photomicrographs of DPF-336 made to represent high salt loadings. The corroded surface is covered with a fairly thick coating of secondary phases and several rectangular crystallites enriched in rare earth elements (two are seen near the bottom of Figure 4c). The crystalline lithium iron phosphate phase that formed as a primary phase was exposed in several regions, as represented in Figure 4d. It is not certain whether the glass phase had dissolved from around the crystals during the test, or if region was not encapsulated by the glass during production. Analyses of cross sections are in progress to better characterize the corrosion behavior and acquire quantitative composition analyses. Both materials were highly fractured prior to testing. (W. Ebert)

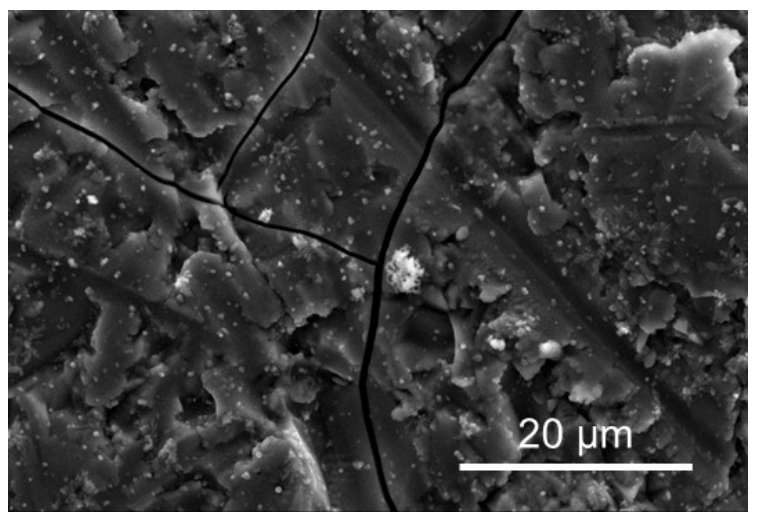

(a)

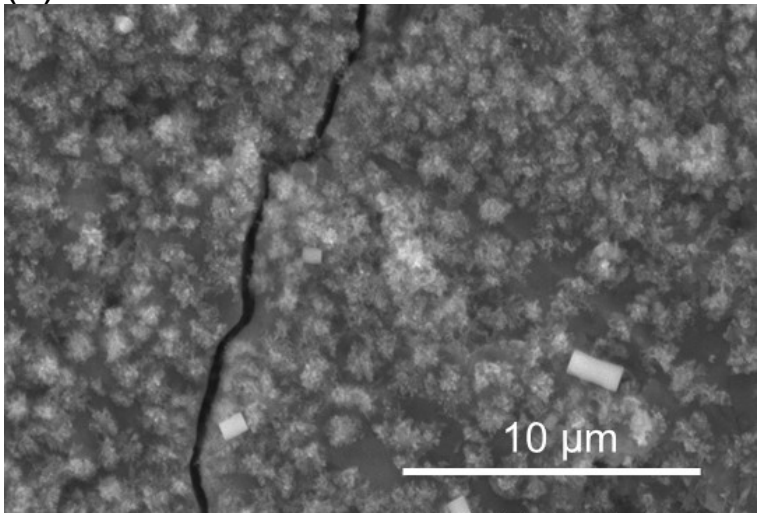

(c)

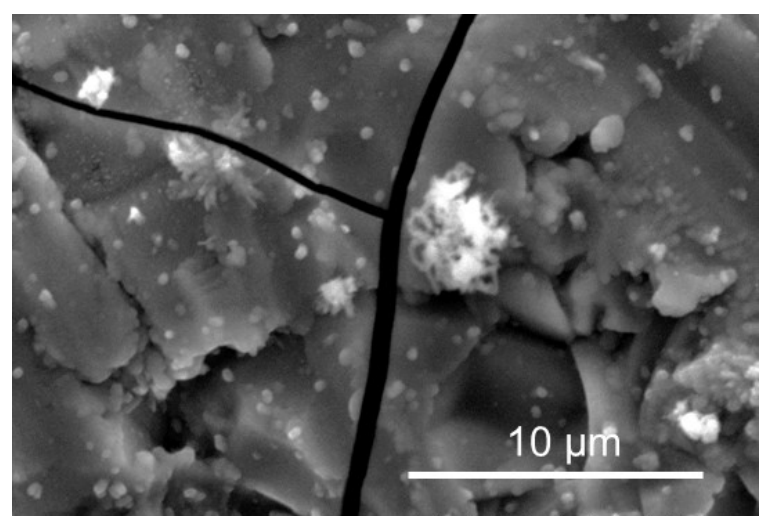

(b)



(d)

Figure 4. SEM photomicrographs of corroded surfaces of (a) and (b) DPF-280 and (c) and (d) DPF-336 after ASTM C1220 tests.

\subsubsection{Mechanisms and Material Behavior}

[ANL] Modified ASTM C1285 PCT tests conducted to assess the effect of the solution composition on triggering Stage 3 behavior have been completed with five DWPF reference glasses and the ISG reference 
glass being used in international collaborations. Correlations between the glass dissolution kinetics and solution composition are being evaluated to support the long-term corrosion model. SEM analyses of the reacted solids are in progress to complement solution analyses. Figure 5 shows some of the secondary phases formed after Stage 3 was triggered for different DWPF reference glasses. (W. Ebert)

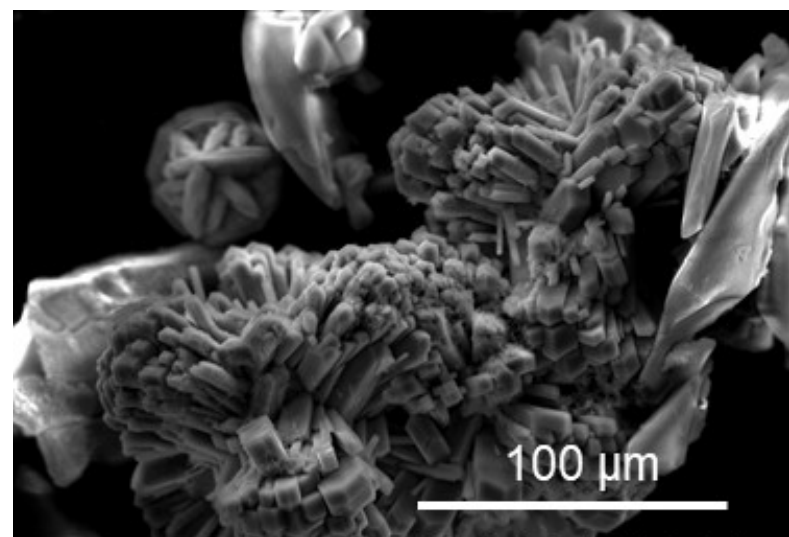

(a) BA-7-11 10

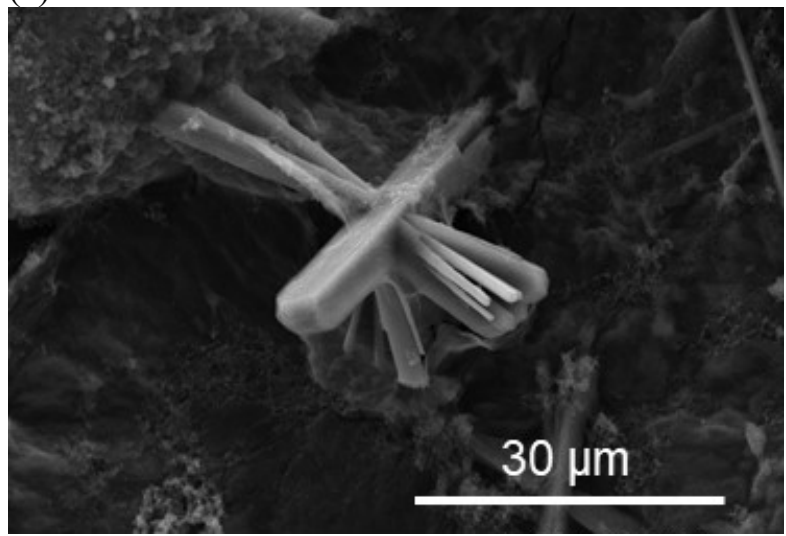

(c) BL-7-11 24

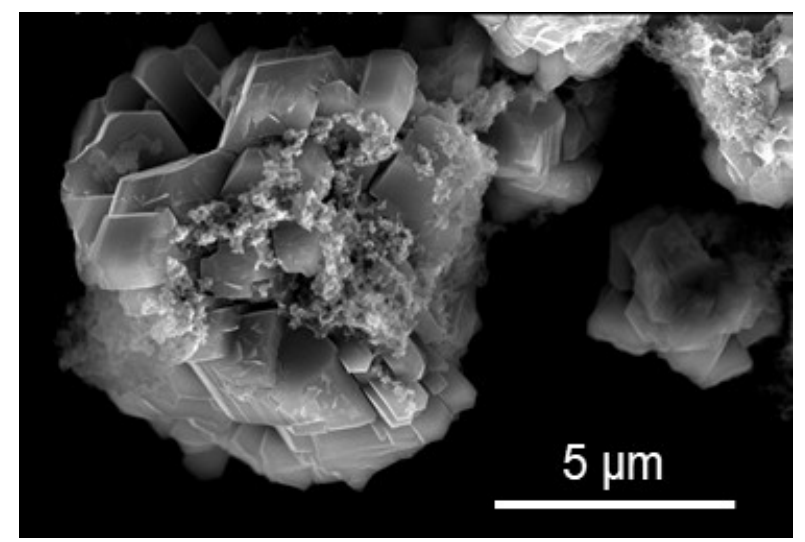

(b) HM-7-7 19

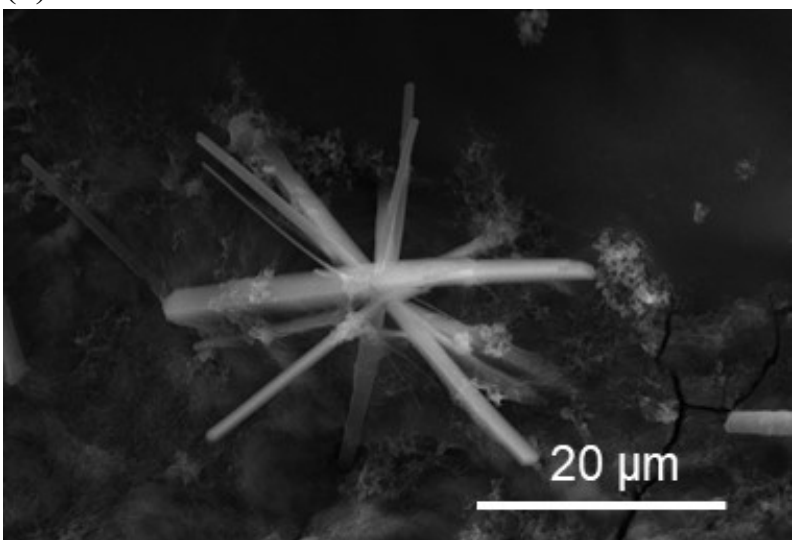

(d) BL-7-11 23

Figure 5. SEM photomicrographs of secondary phases formed when Stage 3 was triggered in tests with (a) DWPF batch glass, (b) DWPF HM glass, (c) and (d) DWPF blend glass.

\subsection{Electrochemical/Molten Salt Processing}

[ANL] The results of electrochemical tests quantifying the effect of $\mathrm{Li}_{2} \mathrm{O}$ concentrations and impurities in $\mathrm{LiCl}$ salt on Zircaloy corrosion was presented at the TMS conference. The combination of methods, including potentiodynamic scans, potentiostatic holds, and electrochemical impedance spectroscopy, combined with direct analysis of the salt composition and SEM analyses provides insights into the effects of molten salt chemistry on corrosion kinetics, corrosion mechanisms, and corrosion products. (W. Ebert)

[ANL] Fabrication of new parts to demonstrate co-deposition at the kilogram scale has been completed and the cell is being assembled. (W. Ebert)

\subsection{Sigma Team - Off-Gas}

[PNNL] A total of $55 \mathrm{~g}$ of $\mathrm{Ag}^{0}$-functionalized silica aerogel $\left(\mathrm{Ag}^{0}\right.$-aerogel) granules was produced at Pacific Northwest National Laboratory and shipped to Oak Ridge National Laboratory for sorption performance testing under simulated vessel off-gas conditions (Milestone: M5FT-20PN030107024). The mechanically robust granules of $\mathrm{Ag}^{0}$-aerogel were produced by an optimized synthesis process, which 
included using a patent-pending technology treatment to strengthen the granules. The manufactured aerogel is the most robust $\mathrm{Ag}^{0}$-aerogel since the start of the project in 2009. There were no fines generated after $60 \mathrm{~min}$. of attrition testing with a vibratory sieve shaker. The $\mathrm{Ag}^{0}$-aerogel had a bulk density of $0.43 \mathrm{~g} / \mathrm{cm}^{3}$ and exhibited iodine sorption capacity $400.5 \pm 2.2 \mathrm{mg}$ of I per $\mathrm{g}$ of $\mathrm{Ag}^{0}$-aerogel. (M. Kubik)

[ORNL] As part of efforts to address the FY 2020 budget, the scopes of the Level 2 milestone, M2FT20OR030107031, and the associated Level 3 milestone were refocused toward off-gas capture needs associated with the processing of advanced reactor metallic fuels. This shift in focus will require some additional data collection beyond the scope of this level 4 milestone. Due to the rescoping effort, little actual progress was made. March activities will focus on identifying the candidate fuels and associated processing methods. The report outline will be revised to reflect the rescoping. (R. Jubin)

[ORNL] Iodobutane permeation tubes were delivered from the vendor, and long-chain organic iodide testing will resume in March. (R. Jubin)

[ORNL] Two extended VOG tests were initiated on May 31, 2019. The first challenges a deep bed of $\mathrm{Ag}^{0} \mathrm{Z}$ with $\sim 50 \mathrm{ppb} \mathrm{I}_{2}$ (balance dry air) at $150^{\circ} \mathrm{C}$. The second challenges a deep bed of $\mathrm{Ag}^{0} \mathrm{Z}$ with $\sim 150$ ppb $\mathrm{CH}_{3} \mathrm{I}$ (balance dry air) at $150^{\circ} \mathrm{C}$. Both tests will be taken down on March 2 and sent for NAA. (R. Jubin)

[ORNL] Work continued on the task to determine the impact of variations in $\mathrm{NO}, \mathrm{NO}_{2}$, and water concentrations on iodine adsorption rates. Test FY20-017 was completed to assess $\mathrm{CH}_{3} \mathrm{I}$ loading under humid conditions at $165^{\circ} \mathrm{C}$ (estimated loading: $105 \mathrm{mg} / \mathrm{g}$ sorbent) and Test FY20-018 was completed to assess $\mathrm{CH}_{3} \mathrm{I}$ loading under humid conditions with $1 \% \mathrm{NO}_{2}$ at $135^{\circ} \mathrm{C}$ (estimated loading: $46 \mathrm{mg} / \mathrm{g}$ sorbent). Three tests remain in the $\mathrm{CH}_{3} \mathrm{I}-\mathrm{AgZ}$ test matrix. (R. Jubin)

\subsection{Material Recovery Pilot Plant}

[ORNL] The parametric study of $\mathrm{HCl}$ dilution in nitrogen has been completed, and the results showed the expected decline in reaction rate with $\mathrm{HCl}$ concentration at constant gas flow rate (10 SLPM). We have also studied the hydrochlorination of Zircaloy-4. Little reaction was observed at $200^{\circ} \mathrm{C}$, but at $350^{\circ} \mathrm{C}$, measurable weight loss was observed over a relatively short period of time. We are planning the study of aluminum- and/or zirconium-clad fuel samples in the hydrochlorination apparatus. We will collect reaction kinetic data on hydrochlorination and removal of the cladding from the fuel samples under conditions that have presented as the best-case for fluidized bed conversion, as determined by earlier tests with the aluminum coupons. We also plan to test for carryover of the $\mathrm{UCl}_{4}$ as an adduct. It is anticipated that we will need about 12 pieces of clad fuel to survey both the effects of aluminum and zirconium cladding.

[ORNL] Based on the initial discussions with INL, the $\mathrm{U}_{3} \mathrm{O}_{8}$ Elutriation experimental system was designed and most of the components ordered. Laboratory set up included establishing ES\&H requirements for handling uranium powders and high pressures. The assembly of the system and initial checkup are expected to be completed in April. (R. Jubin)

\subsection{Polishing and Solidification (Extraction, Conversion, Downblending)}

[INL] INL researchers have successfully completed the first experimental campaign to purify downblended metal HALEU fuel originating from EBR-II driver fuel. The lab scale process utilized three steps: dissolution of the metal fuel in acid, purification via solvent extraction to $>99.9 \%$, and precipitation/calcination to an oxide product. The purified HALEU was successfully produced in oxide forms suitable for use as feed stock for advanced reactor fuel fabrication $\left(\mathrm{UO}_{3}\right.$ and $\left.\mathrm{U}_{3} \mathrm{O}_{8}\right)$. (C. Williams) 
[ANL] Several components need further evaluation to ensure HALEU fuel specifications are met. With regard to the product polishing flowsheet, these include $\mathrm{Sm}, \mathrm{Sn}, \mathrm{Cs}, \mathrm{Ce}, \mathrm{Ru}, \mathrm{Sb}, \mathrm{Sr}, \mathrm{Pu}$, and $\mathrm{Am}$. Antimony ( $\mathrm{Sb}$ ) is a component not currently included in the AMUSE model. It is present as a fission product, and the Sb-125 isotope contributes to the total gamma activity of the HALEU fuel. Literature data for antimony extraction in the nitric acid/TBP/aliphatic diluent system were reviewed and a preliminary D-value model constructed. Based on information in the available references, it is expected that antimony would most likely exist in the pentavalent form as the antimonyl cation $\left(\mathrm{SbO}_{2}{ }^{+}\right)$, which has a maximum D-value on the order of 0.005 over a range of nitric acid and TBP concentrations. Steadystate effluent compositions for the reference flowsheet were recalculated with AMUSE using a modified version of SASPE where Sb was represented with a fixed D-value of 0.005. This resulted in a decontamination factor of $4.14 \mathrm{E}+08$ for antimony for the product, which is expected to be sufficient to meet HALEU fuel specifications. This information will be evaluated within the context of the ECAR4705 calculation. It must be noted that the decontamination factors predicted by AMUSE reflect ideal processing conditions, while the ECAR calculations assume separations that are somewhat less efficient and are intended to be more representative of real-world processing conditions. Other components of interest are undergoing similar evaluation. (C. Pereira)

[ANL] Initial metal prints for 2-cm contactors have been completed and are undergoing post-processing via Central Shops. Once completed, the contactor will be tested hydrodynamically in order to evaluate their performance when compared with plastic 3-D-printed units and the standard ANL stainless steel design. The contactors will then be scaled to $3 \mathrm{~cm}$, as desired, for the UREX system at INL. Preparations are also being made to test the extraction efficiency for the updated rotor design in order to verify that the UREX process chemistry is unaffected. This will be done using iron as a surrogate. This work will begin upon approval and authorization of the Work Control Documents. (C. Pereira)

[PNNL] The report titled, "On-line Measurements Supporting the Hybrid-Zircex Process at INL," was completed and transmitted to personnel at Idaho National Laboratory (INL) to support the High Assay Low Enriched Uranium (HALEU) program. This report assesses the overall Hybrid-Zircex flowsheet with respect to potential locations to insert real-time on-line monitoring based on optical spectroscopy. Within the Hybrid-Zircex program, on-line monitoring could be used at multiple points including liquid and gas-phase processes to identify and quantify multiple target species of interest. Literature and previous demonstrations at PNNL indicate potential target chemical species exhibit uniquely identifiable fingerprints and that optical probes can be integrated into harsh chemical environments. Overall, HybridZircex would see numerous benefits from the addition of chemometric models including enhanced and in situ characterization of chemical processes. This not only allows researchers to better understand and optimize the chemical processes, but also allows operators to control chemical processes in real time. This report fulfills Milestone M3FT-20PN030204046. (Sam Bryan and Amanda Lines)

\subsection{Transportation}

[PNNL] PNNL staff continued to collaborate with ORNL and INL staff to further establish the OptimusL packaging definition and refine the proposed packaging confinement, canister basket, and generic canister definitions. PNNL staff have initiated supporting analyses to support definition finalization. On January 28, 2020, Milestone M5FT-20PN030206033 (originally due February 3, 2020) was submitted. PNNL staff met with INL and ORNL staff regarding conducting interim design discussions at PNNL February 11, 2020. Due to FY-20 budget cuts, this Work Package will receive no FY-20 funds. A modified PICS Work Package will be submitted reflecting PY carryover authorization only, removing FY-20 budget, and deleting further associated obligations and deliverables. Staff will continue to 
collaborate with ORNL and INL staff to further refine and finalize the Optimus-L packaging definition as remaining carryover funds permit. (H. Adkins)

For more information on Material Recovery and Waste Forms Development contact Terry Todd (208) 526-3365 


\section{MPACT CAMPAIGN}

\subsection{Campaign Management}

\subsubsection{NTD \& Management Support}

[LANL] Federal Program Manager, CAM, and NTD developed plans for the annual MPACT spring meeting. The meeting was scheduled for April 7-9, 2020, at Sandia National Laboratories in Albuquerque, New Mexico, but has since been postponed. When rescheduled, the meeting will focus on the Milestone 2020 deliverable and technologies to support the MPACT mission. Federal Program Manager, CAM, NTD, and Ben Cipiti held a telecon to coordinate Milestone 2020 activities and review plans to meet an MPACT Level 2 FY-20 milestone. MPACT personnel developed the Safeguards, Safety, and Security (3S) contribution to the SNFTB white paper.

\subsection{MRWFD/Advanced Nuclear Safeguards and Security Research}

\subsubsection{MSR Safeguards}

[ORNL] The interim report is still in review on the preliminary signatures work, which will be delivered as the level 3 milestone. The team addressed actions for redirection of the scope and completed WP revisions. The PSU NEUP students attended ORNL SCALE training. In addition, we coordinated with NE-5 Advanced Nuclear Reactors Safeguards and Security PM on past FY19 WP scope and planned transition of scope.

\subsubsection{MSR Safeguards Modeling}

[SNL] Current activities are being wrapped up pending transfer of this work to the new NE-5 program area.

\subsubsection{Microcalorimetry Consulting}

[LANL] Successfully demonstrated the ability to quickly "reset" radiation dose effects on the multiplexing chips in the SLEDGEHAMMER detector array. This is an extremely important result to enable deployed microcalorimeter gamma spectrometers, such as the one being developed for Idaho National Laboratory. These spectrometers must operate almost continuously and measure high activity samples. It was determined that illuminating the multiplexing chips with infrared $(1550 \mathrm{~nm})$ light eliminates frequency shifts and instability resulting from gamma dose accumulated during long measurements. The understanding is that the low-energy infrared photons excite a trapped charge which accumulates near the superconducting resonators and degrades their response, without producing additional electron-hole pairs that could be trapped. The new detector array is nearly complete at University of Colorado. Initial results show that it meets design requirements with a much higher pixel yield than the current array and successful implementation of approximately 256 superconducting resonators on one microwave circuit. Delivery to LANL is expected in mid-March.

\subsection{Safeguards and Security Supporting Technologies - Echem}

\subsubsection{Bubbler for Measuring Density and Depth of Molten Salt}

[INL] Results from the laboratory testing (three dip-tubes in 500C molten salt). The first tube was SS and operated at $\sim 4 \mathrm{sccm}$. This tube was the experiment control as it mirrored the HFEF test conditions. The 
second tube was SS but operated at $\sim 10 \mathrm{x}$ flow, and the third was made of Ta metal and operated at $\sim 4$ $\mathrm{sccm}$. Following the 4-week test, the control tube was completely covered in corrosion product on the outside all the way up to the point on the tube that reached the melting point of salt (bottom of baffles). The inside of the tube was nearly completely obstructed from the tip up to the baffles with what appears to be corrosion product and salt (same appearance as the outside of the tube). The second tube (SS, high flow) was also completely covered in corrosion on the outside; however, on the inside, there was only one small section near the bottom of the baffles that had some obstruction $(\sim 50 \%$ of diameter closed). The tantalum tube did not have corrosion product on the outside nor was there any obstruction on the inside of the tube. We are still analyzing results, but it appears Ta may be the most promising material in which to construct a bubbler dip-tube. The existing bubbler in HFEF was cleaned this month. During the cleaning, it was discovered that a hole had developed in the dip-tube, near the baffles. Two new bubbler fixtures were designed and are currently being built. These are short-term-solution bubblers estimated to cost less than $\$ 5,000$ each. They are being made from SS and do not have any new design features from the past bubbler. The purpose of these bubblers is to allow for testing in HFEF during ER operation of LWR fuel. A long-term design may include features such as Ta tubing, replaceable tubes, and offsets from the bottom of the vessel. Paperwork has been submitted to start bubbler testing in high turbulent aqueous solutions (MSR).

\subsubsection{OR Voltammetry}

- [INL] The team continued monitoring the OR, requested and evaluated potentiostat quotes, and analyzed data.

\subsubsection{ER Voltammetry}

[ANL] The sensor is undergoing final qualifications at INL prior to transfer into HFEF. Final preparations are being performed at ANL to ensure that the signal acquisition and analysis systems will be optimally functional when operations begin.

\subsection{Safeguards and Security Milestone 2020 - Echem:}

\subsubsection{Advanced Integration Methods}

[LANL] Finished HDND analysis with new SSPM data and will present the results at the technical exchange. Moving onto the Microcal which requires a new model to be built.

\subsubsection{Safeguards Facility Models}

[SNL] The current Safeguards Model has been compared to the ANL flowsheet modeling results to check for consistency. No significant issues have been found. The team is currently working on getting final numbers for measurement technology uncertainties to use in the model.

\subsubsection{Milestone 2020 Coordination}

[SNL] A draft overview paper for the JNMM submission was completed for circulation to the other laboratories. This work started earlier than originally planned due to requiring input from other PIs. 


\subsubsection{Security Facility Models}

[SNL] The vulnerability analysis is proceeding, and some scenarios are beginning their runs in the tabletop tool. Initial results will be presented at the Spring MPACT meeting.

For more information on MPACT contact Mike Browne at (505) 665-5056. 


\section{SYSTEMS ANALYSIS AND INTEGRATION (SA\&I) CAMPAIGN}

\subsection{Campaign Management}

[ANL, INL, BNL, ORNL] Campaign leaders worked with lab leads to revise the work packages in order to modify their spending plans and also to change information (scope and deliverable description) on three activities within their work packages.

[ANL, INL, BNL, ORNL] Developed information on where the campaign could support future efforts on the DOE-NE Advanced Reactor Demonstration program.

\subsection{Nuclear Energy System Performance (NESP)}

\subsubsection{Technology Maturity \& Economic Performance Potential of Microreactors}

[ANL] A breakdown of the technology areas of the Holos microreactor was done to support the TSRA and cost analyses. The team identified the critical technologies of the Holos microreactor and started work on the technology readiness-level assessment questionnaire.

[INL] INL staff met to coordinate the approach and analysis of the microreactors. Staff then developed a preliminary methodology for cost estimating, applied to microreactors. INL staff developed preliminary analyses and conducted an internal review of the approach.

[ANL] Staff gathered information to develop new algorithms for estimating components that currently do not exist in ACCERT. Top-down estimates were made that suggest a very high direct overnight cost. The team is working to reduce areas where the methodology does not apply, and understand differences with top-down estimates.

\subsubsection{Impacts of Foreign Energy Transition Policies}

[ANL] Staff drafted the level 3 milestone report to describe the impacts of the energy policy transition of Korea, Germany, and Japan. The report contains the impacts of energy policy transition on the national economy, $\mathrm{CO}_{2}$ emission, energy mix, and profit structure of utility companies, etc.

[PNNL] Awaiting completion of draft report on Impact of Foreign Energy Transition Policies to provide review comments.

\subsubsection{Factors Impacting Nuclear Energy Share}

[ANL, BNL, INL, ORNL] The team continued their collection of information on the sustainability of nuclear energy in future markets and policy environments from OECD/NEA, university, and consulting companies, etc.

\subsubsection{Re-use of Decommissioned Nuclear Assets}

[ANL, BNL, INL, ORNL] Regular bi-weekly calls to review information on the decommissioned nuclear assets were held.

[ORNL] Data was compiled on the US decommissioned site, which may serve as a location for future SMR/advanced reactor deployment. The intention is to use OR-SAGE to survey these sites from a siting perspective. 


\subsubsection{FCDP Development for Specific Advanced Reactors}

[ORNL] A resource has been found and allocated to this task. This early career professional is new to the campaign and to developing FCDPs, and has therefore been spending some time getting up to speed with previous FCDPs in order to understand the proper approach to developing them.

\subsubsection{Maintain/Update of Fuel Cycle Catalog}

[SNL] We continued to maintain the catalog, checking it weekly to ensure every component is working properly, correcting any problems that are found.

\subsubsection{Transition Analysis Studies and Tools Development}

[ORNL] A draft report on the user interface for Cyclus has been completed and issued within the team for review and comment.

[ORNL] A draft report on the fuel cycle modeling uncertainty quantification, sensitivity study, and optimization capability has been completed and issued for comment. Those comments are now being incorporated.

[ANL] Provided quick-turnaround, high-impact strategic goals for FY-21-22 for the Transition Analysis activities within the SA\&I Campaign, including evaluating the utilization of existing and future fuel resources for future nuclear systems. Completed implementing an economics model in DYMOND and its coupled DAKOTA framework for sensitivity and uncertainty calculations. SA/UQ base scenario was also adjusted to allow for sufficient parameter variations while avoiding fuel shortages. During this testing, several bugs in the DYMOND code were found and most were resolved.

[ORNL] A test version of the user interface for Cyclus has been completed and was issued to the other lab participants for testing.

\subsubsection{Quick Turn-Around Studies.}

[ANL] Staff reviewed a write-up from the campaign federal manager on advanced nuclear fuel cycles and supported the final product with a memo on the time evolution of the waste radiotoxicity values from once-through and continuous recycling fuel cycles.

\subsection{Economic and Market Analysis For Nuclear Energy Systems (EMANES)}

\subsubsection{Improvement of ACCERT Algorithm}

[ANL] The indirect cost components of the PWR-BE were reviewed. Indirect costs are made up of many items. These include temporary construction facilities, construction tools and equipment, payroll insurance and taxes, home office services, field supervision, home quality assurance, field quality assurance, startup costs, permitting, etc. Most of these have many sub-elements. An overall method applicable to very different designs and scale, particularly factory fabricated instead of stick built, will require a significant set of algorithms be developed for these various costs included in the indirect cost category.

[INL] INL staff continued ongoing collaboration with ANL staff regarding algorithm enhancements. INL staff reviewed published documentation on ACCERT as well as documents undergirding ACCERT. 


\subsubsection{Daily Market Analysis of Load Following and Storage Impacts}

[ANL] An organized meeting was held on February 13, 2020, where we reviewed the time-modeling strategy in different capacity expansion codes (GCAM, MARKAL, ReEDS, and A-LEAF). Staff met on February 28 with Energy System division experts to discuss progress on daily market analyses (EMANES Act 2.1). They extracted historic 2019 data (load, wind, solar, ancillary services, etc.) from the ERCOT region. Those data were received from the ERCOT market and extracted into an A-LEAF format. A memo was developed and sent to INL for synthetic data generation and for complementary analyses based on the ERCOT model.

\subsubsection{Cost Basis Report Enhancements}

[ANL] A "What-It-Takes" spreadsheet was developed to track future changes and allow automated updates of the year-of-dollars in order to generate tables and figures for use in the CBR. The spreadsheet is largely complete and was updated to the INL Sharepoint. Currently, this results in breaking the links between the many files used to make it easier to manage are lost. Hansen (INL) is looking into this with INL technical support.

[INL] INL staff continued to collaborate with ANL staff on plans and implementation to updates to the CBR.

\subsubsection{Regional and Global Analysis}

[PNNL] Completed GCAM modeling simulations of long-term nuclear energy scenarios for deep decarbonization for supporting draft paper on the role and value of nuclear energy for addressing climate change. The team is in the process of preparing a draft paper suitable for journal publication.

[PNNL] The team participated in the Daily Market Analysis project to assess the capabilities of electric power sector models and their ability to address associated impacts of intermittent or variable energy generation.

\subsubsection{Lessons-Learned from LWR Deployment History}

[INL] INL staff met with staff from BNL and a post-doc collaborator working at INL. INL staff gathered materials into a draft outline and circulated to the team for review. They constructed a visual analytical tool for presenting key concepts in LWR deployment.

\subsubsection{Adaptation of OR-SAGE for NES Analysis}

[ORNL] The team has worked with ORNL's IT department to create a virtual machine on an ORNL enterprise server to allow us to publish the OR-SAGE tool as an external-facing platform for other users.

[ORNL] A number of tasks have been completed as part of the OR-SAGE back-end design and development:

- Implemented login access for factor rating to allow specific users to provide rank information for data layers impacting suitability

- Implemented a sign-up page to allow users to create accounts if they do not have an existing account

- Created the interface to allow user input for ranking each factor 
- The web application is now implemented using Java Server Pages, and connection to the database for the login access, account registration/sign-up is implemented using servlet and JDBC connection between the front page and PostgreSQL database.

In addition, the team has discussed with EIA staff getting regional-level nuclear energy generation projections.

[ORNL] Work has continued to support the University of Michigan (UM) to determine how the ORSAGE development work might dovetail with an ARPA-E project proposed by UM to support policy decisions that impact reactor projects and reactor siting. Following the meeting, a work proposal was prepared detailing how ORNL could support this effort. In addition, a separate inquiry has been received from the University of Illinois at Urbana-Champaign (UIUC) on how OR-SAGE may be able to support the UIUC desire to host a microreactor.

For more information on Systems Analysis and Integration contact Temitope Taiwo (630) 252-1387. 


\section{JOINT FUEL CYCLE STUDY ACTIVITIES}

Two Level 2 milestones were completed:

- Deliver 2019 program report to JFCS stakeholders

- Prepare 2020 Nuclear Technology Transfer sheets for JFCS steering committee review.

The third $4 \mathrm{~kg}$-scale electrorefining test with reduced irradiated LWR fuel was completed. The fourth 4 $\mathrm{kg}$ electrorefining test was initiated.

Several stakeholder meetings were held for continued collaboration, including:

- $\quad$ SSWG meeting in Vienna January 21-23

- $\quad$ Experts meeting on waste forms at ANL, February 18-20

For more information on Joint Fuel Cycle Studies Activities contact Ken Marsden (208) 533-7864. 


\section{AFCI-HQ PROGRAM SUPPORT}

Site: University Research Alliance at West Texas A\&M University in Canyon, Texas, and the following universities: Ohio State University, University of Tennessee at Knoxville, Georgia Institute of Technology, University of Idaho, Colorado School of Mines, University of South Carolina, Florida State University, Northwestern University, Clemson University, North Carolina State University, University of Utah, University of Chicago, Columbia University, University of Toledo, and other universities.

Universities engaged in Nuclear Technology research via URA programs since 2001:

Boise State University

Boston College

Clemson University

Colorado School of Mines

Columbia University

Georgia Institute of Technology

Georgetown University

Idaho State University

Florida International University

Florida State University

Kansas State University

Massachusetts Institute of Technology

Missouri University of Science and

Technology

North Carolina State University

Northern Illinois University

Northwestern University

Ohio State University

Oregon State University

Pennsylvania State University

Purdue University

Rensselaer Polytechnic Institute

Rutgers University

Texas A\&M University

University of Arkansas
University of California at Berkeley

University of California at Santa Barbara

University of California at Davis

University of Chicago

University of Cincinnati

University of Florida

University of Idaho

University of Illinois at Urbana-Champaign

University of Michigan

University of Missouri

University of Nevada at Las Vegas

University of New Mexico

University of North Texas

University of Notre Dame

University of Ohio

University of South Carolina

University of Tennessee at Knoxville

University of Texas at Austin

University of Toledo

University of Utah

University of Virginia

University of Wisconsin

Vanderbilt University

Virginia Commonwealth University

Washington State University 


\subsection{Innovations in Nuclear Technology R\&D Awards}

\subsubsection{University Programs}

\subsubsection{Summary Report}

The University Research Alliance continued to send out the program announcement for the 2020 Innovations in Nuclear Technology R\&D Awards competition, and to accept and process applications from students. The program was announced on January 24.

University Research Alliance conducts a significant outreach effort to acquire the applications. The announcement is sent to thousands of faculty in relevant disciplines at universities throughout the United States. The announcement is also sent to a number of web sites including the American Nuclear Society, the Nuclear Energy Institute, and science.gov. It is also sent to ANS student chapter presidents, INMM student chapter presidents, and university research centers that conduct nuclear technology research. Students and their advisors who have won awards in previous years are informed of the opportunity so that they may apply again, if eligible, and pass the information on to their colleagues. Announcements are sent to nuclear engineering department heads, and faculty who are known to be conducting nuclear technology research.

The outreach objective is to ensure that every student who may be eligible for an award is informed of the opportunity. The number of applications has increased slowly over the life of the program, but the pool of potential applicants is a small one. The number of applicants is significantly affected by the amount of research any one faculty member may be conducting, and the stage of the research. It seems clear that university research support and this type of university program are essential to educating students with expertise specific to nuclear technology.

The vast majority of applications are usually received in the final week, with many of those being received in the two days before the deadline. The scheduled deadline for 2020 is midnight Sunday March 15.

To apply, a student submits an application and a recently published paper on which the applicant is the first author or the primary student author. There are three competitions:

\section{Open Competition}

Publications from eligible students at all universities are eligible for this competition. Awards are $\$ 3,000$ for First Place and \$2,500 for Second Place in each of the following categories:

- Advanced Fuels (including in-core materials and cladding, material science, in-core instruments, detectors, sensors, and nanoscale structures and materials)

- Advanced Reactor Systems (including material science, advanced alloy development and testing, nuclear physics, nuclear reactor thermal hydraulics, fast reactor concept development, and advanced reactor design)

- Energy Policy (including decision support simulators, which may include game theory, economic modeling, and applied mathematics)

- Material Protection, Control, and Accountancy (including instrumentation, detectors, and sensors for safeguards and nonproliferation applications)

- Material Recovery and Waste Form Development (including advanced extraction technology for dry and wet recycling of used nuclear fuel, advanced waste form development and its characterization, and uranium resources, thermodynamics, and kinetics) 
- Nuclear Science and Engineering (including nuclear physics, nuclear chemistry, radiochemistry applicable to R\&D nuclear fuel cycle, and generic geology repository)

- Used Fuel Disposition (including storage, transportation, disposal of commercial used fuel, and behavior of actinides and radionuclides under generic repository conditions)

Competition for Students Who Attend Universities with Less Than \$600 Million in 2017 Science and Engineering R\&D Expenditures

Publications from students at universities which have lower research outlays are eligible for this competition. Awards are $\$ 1,500$ each for five students.

Undergraduate Competition

Publications from undergraduate students at all universities are eligible for this competition. Awards are $\$ 1,000$ each for up to five students.

University Research Alliance has been removing email addresses for rejected announcement emails and removing addresses of people who have asked to be unsubscribed from the list. This process will continue with each announcement.

University Research Alliance continued preparations for the 2020 Innovators' Forum, scheduled for May 26-28.

For more information on the University Research Alliance contact Cathy Dixon (806) 651-3401. 